\title{
Verzeichnis der Tagungsteilnehmer
}

PD Dr. Monika Bernett, München

Prof. Dr. Christer Bruun, Toronto

Dr. Fabian Goldbeck, Berlin

Prof. Dr. Rudolf Haensch, München

Dr. Olivier Hekster, Nijmegen

Prof. Dr. Ralf von den Hoff, Freiburg

Prof. Dr. Martin Hose, München

Prof. Dr. Christian Meier, Hohenschäftlarn

Dr. Christian Ronning, München

Dr. Dirk Schnurbusch, Freiburg

PD Dr. Gunnar Seelentag, Köln

Prof. Dr. Natascha Sojc, Leiden

Prof. Dr. Dieter Timpe, Würzburg

Prof. Dr. Uwe Walter, Bielefeld

Prof. Dr. Aloys Winterling, Berlin (Stipendiat des Historischen Kollegs 2006/07)

Prof. Dr. Christian Witschel, Heidelberg

Prof. Dr. Reinhard Wolters, Wien

Prof. Dr. Martin Zimmermann, München 
